\title{
In vitro quality evaluation of metformin hydrochloride tablets marketed in Addis Ababa
}

\author{
H. Kassahun ${ }^{1,2}$, K. Asres ${ }^{2}$, A. Ashenef ${ }^{2 *}$ \\ ${ }^{I}$ Department of Pharmacy, College of Health Sciences, Wollo University, P.O. Box. 1145 Dessie, Ethiopia \\ ${ }^{I}$ Department of Pharmaceutical Chemistry and Pharmacognosy, College of Health Sciences, Addis Ababa University, \\ P.O. Box. 1176, Addis Ababa, Ethiopia
}

Received: 13 May 2018

Revised: 27 May 2018

Accepted: 03 December 2018

DOI: https://doi.org/10.3329/bjsir.v54i2.41674

\begin{abstract}
In this study, an attempt was made to assess quality as well as pharmaceutical equivalence of six brands of metformin hydrochloride tablets marketed in Addis Ababa using in vitro methods. Friability, disintegration, dissolution and assay for the content of active ingredients were evaluated using the methods described in the United States pharmacopeia (2007). All the brands of metformin hydrochloride tablets complied with the official specification for hardness, friability, disintegration and assay. Five brands of metformin hydrochloride complied with the USP dissolution tolerance limits but Metformin Denk failed to release the stated amount. Statistical comparison for in vitro drug release indicates that some of the products of metformin hydrochloride tablets showed significant difference $(\mathrm{P}<0.05)$, indicating difference in their in vitro drug release that might affect the in vivo bioavailability and the bioequivalence of the products.
\end{abstract}

Key words: Metformin hydrochloride; Physicochemical bioequivalence; Drug release; Drug quality

\section{Introduction}

Diabetes mellitus (DM) is a group of metabolic disorders characterized by hyperglycemia, altered metabolism of carbohydrates, fats and proteins with an increased risk of complication of vascular diseases. It results from defects in insulin secretion, insulin sensitivity, or both (Barbara et al., 2009). The increasing prevalence of DM in the world and also in developing countries, the emergence of diabetes complications as a cause of early morbidity and mortality and the enormous and mounting burden on health care systems make diabetes a priority health concern (Khatib, 2006). Long-term complications of diabetes include retinopathy, nephropathy, peripheral neuropathy, amputations and sexual dysfunction (Bastaki, 2005).

Pharmaceuticals are used primarily to save life and to prevent long-term diabetic complications. There has been a global increase in the prevalence of Type 2 DM due to life style changes such as poor diet, decreased physical activity and stress (Wild et al., 2004). This type of DM requires the use of oral hypoglycemic agents when dietary control and exercise have proved inadequate (Katzung et al., 2012). Oral hypoglycemic agents include biguanides (metformin), sulphonylureas (tolbutamide, glibenclamide) and thiazolidinediones (glitazones) (Bastaki, 2005).

Metformin belongs to the biguanide class of oral hypoglycemic agents and is a widely used antidiabetic drug for the management of type II DM (Sahra et al., 2010). Chemically it is N, N-dimethyl imidodicarbonimidic diamide hydrochloride $\left(\mathrm{C}_{4} \mathrm{H}_{11} \mathrm{~N}_{5}, \mathrm{HCl}\right)$ with a molecular weight of 165.6 (Najib et al., 2002). Metformin hydrochloride decreases intestinal absorption of glucose, suppresses glucose production, especially hepatic gluconeogenesis and improves peripheral tissue insulin sensitivity by increasing peripheral glucose uptake and utilization (Poretsky, 2010). 
Many generics of metformin hydrochloride tablets are available within the drug supply system globally after the expiration of patent on the innovator brand. Different reports on comparative in vitro quality evaluation of generics of metformin hydrochloride tablets of different countries have been published. Olusola et al. (2012) evaluated eight brands of metformin hydrochloride $500 \mathrm{mg}$ tablets available in Lagos, Nigeria and showed that only four brands could be regarded as being biopharmaceutically and chemically equivalent. In addition, Zakeri-Milani et al. (2012) evaluated eight generic metformin hydrochloride tablets which are available in Iran market and reported that all except one generic product were bioequivalent with the innovator brand. Moreover, Bhavanam et al. (2010) evaluated four brands of metformin hydrochloride tablets available in India and found out that all the products met the requirements as per general specifications of Indian Pharmacopoeia. Preliminary physicochemical assessment of drug products has a paramount importance in ensuring the quality of drug products. Generic drug products must satisfy the same standards of bioavailability or bioequivalence studies which may involve both in vivo and in vitro studies (Chereson, 1996). Assessment of bioequivalence of the different generic products available in the market is very important to ensure that generic drugs being sold can be used interchangeably with the branded products (Fahmy and Gharbieh, 2014). generic substitution. Oral metformin are widely used in Ethiopia with several new brands introduced into the Ethiopian market in recent years. Variety of drugs in circulation often put clinicians and pharmacists into difficult situation of choice and the possibility of interchangeability among brands (Olusola et $a l ., 2012$ ). Use of substandard products may lead to poor blood glucose control and life threatening complications. Despite widespread presence of NIDDM in Ethiopia and extensive use of metformin, there are no reports on the bioavailability and bioequivalence of the various brands in the country. Hence, the present study was carried out to assess the quality and pharmaceutical equivalence of metformin tablets available in the Ethiopian market.

\section{Materials and methods}

\section{Materials and reagents}

The chemicals and reagents used to perform the experiments were the following: $500 \mathrm{mg}$ metformin hydrochloride tablets, monobasic ammonium phosphate (FARMITALIA CAROERBA, Italy), sodium hydroxide (BDH limited, Poole, England), potassium phosphate monobasic (Fisher Scientific, USA), and distilled water. Different brands of $500 \mathrm{mg}$ metformin hydrochloride tablets were bought from various pharmacy retail outlets in Addis Ababa. All the brands used were within their shelf life at the time of study. The detailed

Table I. Product description of metformin hydrochloride tablets

\begin{tabular}{|c|c|c|c|c|}
\hline Brand & Manufacturer & Batch Number & Mfg. date & Exp. date \\
\hline Bigomet & $\begin{array}{l}\text { ARISTO Pharmaceuticals } \\
\text { Pvt. Ltd., (India) }\end{array}$ & M101E011E & $05 / 2011$ & $04 / 2014$ \\
\hline Brot & Medscheme Ltd, (Cyprus) & A6F099 & $06 / 2012$ & $06 / 2017$ \\
\hline Diabetamin & HOVID Bhd., (Malaysia) & BB08422 & $08 / 2011$ & $08 / 2014$ \\
\hline Glucomet & $\begin{array}{l}\text { Y.S.P Industries SDN. BHD., } \\
\text { (Malaysia) }\end{array}$ & VJ012 & $10 / 2011$ & $10 / 2014$ \\
\hline Metformin Denk & $\begin{array}{l}\text { DENK PHARMA GMBH \& } \\
\text { CO.KG., (Germany) }\end{array}$ & 80B & $02 / 2013$ & $01 / 2018$ \\
\hline Neomid & AEGIS LTD., (Cyprus) & 12176 & 08/2011 & 07/2014 \\
\hline
\end{tabular}

The introduction of generic drug product from multiple sources into the health care delivery system of many developing countries has been accompanied by a variety of problems of which the most critical is the widespread distribution of fake and substandard drug products (Bano et $a l ., 2011)$. The increasing use of metformin hydrochloride tablets in clinical practice creates the need to monitor and ascertain the quality of the various brands available in the drug market for quality control assessment and for purpose of descriptions of these products are presented in Table I. Standard metformin hydrochloride was obtained from EFMHACA and is of USP reference standard. All chemicals used were analytical grade.

\section{Equipment}

The following equipment were used for the experiment: analytical balance (Mettler Toledo, Switzerland), hardness tester (Schleuniger, 2E/205, Switzerland), friability tester 
(ERWEKA, TAR 20, Germany), disintegration apparatus (CALEVA, G.B. Caleva Ltd., UK), dissolution apparatus (ERWEKA, DT600, Germany), UV-Visible Spectropho tometer (Single beam Spectrophotometer, CM2203, Belarus), filter paper (diameter 110, lot ER0692-1, Schleicher and Schuell, Germany) and PH meter (Mettler Toledo, Switzerland).

\section{Methods}

Drug quality assessment experiment was done using pharmacopeial procedures described in the USP/NF XXIV, USP (USP/NF 25, 2007).

\section{Hardness test}

The hardness of each tablet was determined by selecting six tablets randomly using a hardness tester. Each tablet was placed between two anvils and force was applied to the anvils, and the crushing strength that causes the tablet to break was recorded. Crushing strength of average of six tablets was recorded.

\section{Uniformity of dosage units}

The dosage uniformity of metformin hydrochloride tablets was evaluated by weight variation, where twenty tablets from each of the six brands were selected by chance, weighed individually with an analytical balance. The average weights for each brand as well as the percentage deviation from the mean value were calculated.

\section{Friability test}

Ten tablets from each brand was dedusted and weighed on the analytical balance. Tablets were placed in the drum of the friability tester rotated at 25 revolutions per minute (rpm) for four minutes (100 times). Then, tablets were weighed and were compared with their initial weights and percentage friability was calculated.

\section{Disintegration time}

Six tablets were placed in a disintegration tester filled with distilled water at $37 \pm 0.5^{\circ} \mathrm{C}$. The tablets were considered completely disintegrated when all the particles are passed through the wire mesh and time was recorded.

\section{Chemical assay}

Assay of metformin hydrochloride is carried out according to USP/NF (2007) specification. Standard preparation: metformin hydrochloride standard was dissolved in distilled water to obtain $0.01 \mathrm{mg} / \mathrm{ml}$ concentration of the standard solution. From the stock solution, serial dilutions were made to obtain calibration concentrations of $0.007 \mathrm{mg} / \mathrm{ml}, 0.008$ $\mathrm{mg} / \mathrm{ml}, 0.009 \mathrm{mg} / \mathrm{ml}, 0.01 \mathrm{mg} / \mathrm{ml}$ and $0.012 \mathrm{mg} / \mathrm{ml}$.

Sample preparation: twenty tablets of each brand were crushed separately and finely powdered. An accurately weighed portion of the powder was transferred, equivalent to about $100 \mathrm{mg}$ of metformin hydrochloride, to a $100 \mathrm{ml}$ volumetric flask. Water $(70 \mathrm{ml})$ was added, shaken by mechanical means for $15 \mathrm{~min}$, diluted with water to volume, and filtered, discarding the first $20 \mathrm{ml}$ of the filtrate. The filtrate $(10 \mathrm{ml})$ was diluted with water to $100 \mathrm{ml}$ and $10 \mathrm{ml}$ of the resulting solution was further diluted with water to 100 mlto obtain $0.01 \mathrm{mg} / \mathrm{ml}$ sample solution. The active pharmaceutical ingredient content of sample solutions was determined by measuring their absorbance against the reagent blank at $232 \mathrm{~nm}$ using an Ultraviolet (UV) visible Spectrophotometer.

\section{Dissolution test}

The dissolution of metformin hydrochloride was done using dissolution apparatus type II (paddle apparatus) with the rate of $50 \mathrm{rpm}$ at $37 \pm 0.5^{\circ} \mathrm{C}$ on six tablets of each brand. The dissolution medium was $900 \mathrm{ml}$ phosphate buffer $(\mathrm{pH}=6.8)$. $10 \mathrm{ml}$ sample was withdrawn at 10, 20, 30, 45, and $60 \mathrm{~min}$ and an equivalent amount of fresh dissolution medium, maintained at equal temperature, was replaced. Filtered samples were then appropriately diluted (100 fold dilutions) and absorbance readings were taken with UV/Visible Spectrophotometer at wavelength of $232 \mathrm{~nm}$. Solutions of metformin working standard was also prepared using dissolution medium and absorbance was measured. Phosphate buffer was used as a blank. The concentration of each sample was determined from calibration curve and the percent of drug release at each time was calculated.

\section{Data analysis}

Data obtained was treated using ORIGIN ${ }^{\circledR}$ graphing and scientific analysis software program, Microsoft Excel 2007 and Windows SPSS Version 20. Comparison and statistical significance was determined by one-way analysis of variance (ANOVA). All data were analyzed at a 95\% confidence interval $(\mathrm{P}<0.05)$.

\section{Results and discussion}

\section{Uniformity of dosage forms}

The result of weight uniformity test is shown in Table II. All the brands complied with the USP (2007) specification for uniformity of weight as none had percentage deviation in weight greater than $5 \%$. 
Table II. Weight variation of different brands of metformin hydrochloride tablets

\begin{tabular}{lllllll}
\hline Products & Met. Denk & Brot & Neomid & Bigomet & Glucomet & Diabetamin \\
\hline $\begin{array}{l}\text { Weight } \\
\text { (mg) } \pm \text { SD }\end{array}$ & $668.76 \pm 6.0$ & $680.92 \pm 4.8$ & $599.05 \pm 4.1$ & $687.32 \pm 7.5$ & $561.88 \pm 4.5$ & $564.1 \pm 12.3$ \\
$\begin{array}{l}\text { \% Deviation } \\
\text { (Range) }\end{array}$ & $(-1.07,1.53)$ & $(-1.03,1.3)$ & $(-1.48,0.81)$ & $(-1.66,1.71)$ & $(-1.26,1.21)$ & $(-3.81,4.04)$ \\
\% RSD & 0.90 & 0.71 & 0.68 & 1.09 & 0.80 & 2.18 \\
\hline
\end{tabular}

Weight uniformity test is required to ensure that the drug content in each unit dose is distributed in a narrow range around the label strength (USP, 2007). Uniformity of weight serves as a pointer to good manufacturing practices as well as amount of the API contained in the formulation (Oishi et al.,2011) and it is an important parameter because high weight variation indicates variation in amount of active ingredients and/or chemical additives. Variation of active ingredients may lead to toxicity, ineffectiveness or unpredictability of action of the product while variability of additives may affect other physicochemical characteristics of the product and ultimately alter the bioavailability of the drug (Ogah and Kadejo, 2013).

\section{Hardness and friability test}

The mean hardness values of metformin hydrochloride tablets are shown in Table III. The results showed that the brands had mean hardness value within the range of 156.5 $\pm 7.86-199.5 \pm 0.836 \mathrm{~N}$ for metformin hydrochloride tablets. For metformin hydrochloride tablets studied, Bigomet had the highest hardness value $(199.5 \pm 0.836 \mathrm{~N})$ while Neomid had the lowest value $(156.5 \pm 7.86 \mathrm{~N})$.

A force of about $40 \mathrm{~N}$ is the minimum requirement for satisfactory tablet hardness (Oishi et al., 2011). Hence, the tablets of all brands of metformin hydrochloride were satisfactory for hardness. Similarly, the weight loss of the tablets after friability test expressed as percent friability is indicated in Table III. The lowest and highest percent friability for metformin hydrochloride tablets has been obtained for Bigomet (0.036) and Neomid (0.127), respectively.

The USP (2007) states that the friability value of tablets should be less than $1 \%$ and the results showed that all the brands of metformin hydrochloride tablets had friability values ranging from $0.036-0.127 \%$ and thus, all brands passed the friability specification. Brands of metformin hydrochloride tablets with higher crushing strength showed low friability value. Generally, all the studied metformin hydrochloride tablets passed hardness and friability test.

Hardness or crushing strength of tablets is an important parameter which helps to assess the resistance of the tablet to breakage under condition of storage, transportation and handling (Odeniyi et al., 2003; Bano et al., 2011). Therefore, it can influence friability, disintegration and dissolution. Excessive hardness of tablets would prolong disintegration time, thereby affecting dissolution and absorption rates, bioavailability and onset of action of the drug. Soft tablets, on the other hand, are unable to withstand conditions of storage, transportation and handling without breaking or chipping. It is, therefore, important that tablets are of optimum hardness. Factors affecting the strength of tablets include the amount of binders used in granulation and the pressure applied during compression of the tablets (Oishi et al., 2011; Ogah and Kadejo, 2013). Friability test is closely related to tablet hardness and is designed to evaluate the ability of the tablet to withstand abrasion in coating, packaging, handling and transporting and other manufacturing processes (Kishore and Amareshwar, 2012). Generally, adequate tablet hardness as well as reasonable friability is required for consumer acceptance (Hailu et al., 2011).

\section{Disintegration test}

The mean disintegration times of the different brands of metformin hydrochloride tablets are shown in Table IV. The results showed that all the brands passed the disintegration test according to USP (2007), which specifies $30 \mathrm{~min}$ for uncoated and film coated tablets.

As shown in Table IV, the disintegration times for metformin hydrochloride tablets had fallen within the acceptable range. Brot $(6.44 \pm 1.64)$ and Diabetamin (6.17 \pm 0.86$)$ with low values are possibly attributed to the presence of large amounts of disintegrants (Muaz et al., 2009). These, coupled 
Table III. Hardness and friability tests of different brands of metformin hydrochloride tablets

\begin{tabular}{llll}
\hline Drug product & Brand & Hardness $(\mathrm{N}) \pm \mathrm{SD}$ & Friability (\%) \\
\hline & Bigomet & $199.5 \pm 0.836$ & 0.036 \\
& Brot & $195.5 \pm 4.8$ & 0.046 \\
Metformin 500 mg & Diabetamin & $197.83 \pm 1.6$ & 0.039 \\
& Glucomet & $170.66 \pm 6.15$ & 0.116 \\
& Metformin Denk & $168.66 \pm 4.72$ & 0.117 \\
& Neomid & $156.5 \pm 7.86$ & 0.127 \\
\hline
\end{tabular}

Table IV. Disintegration tests and percentage drug content of different brands of metformin hydrochloride tablets

\begin{tabular}{|c|c|c|c|}
\hline Drug product & Brand & Disintegration time $\pm \mathrm{SD}$ & Assay $(\% \mathrm{~W} / \mathrm{W} \pm \mathrm{SD})$ \\
\hline \multirow{6}{*}{ Metformin $\mathrm{HCl} 500 \mathrm{mg}$} & Bigomet & $12.65 \pm 0.99$ & $101.64 \pm 4.14$ \\
\hline & Brot & $6.44 \pm 1.64$ & $97.18 \pm 2.2$ \\
\hline & Diabetamin & $6.17 \pm 0.86$ & $100.166 \pm 2.88$ \\
\hline & Glucomet & $14.34 \pm 0.43$ & $103.78 \pm .06$ \\
\hline & Metformin Denk & $15.69 \pm 0.83$ & $103.85 \pm 0.12$ \\
\hline & Neomid & $10.16 \pm 0.43$ & $97.28 \pm 2.249$ \\
\hline
\end{tabular}

with the excellent crushing strength observed suggest that there is a good balance between mechanical strength and release properties. Metformin Denk $(15.69 \pm 0.83)$ and Glucomet $(14.34 \pm 0.43)$ had relatively highest disintegration time.

Tablet disintegration is prerequisite to dissolution and subsequent absorption of a drug from the dosage form. A drug incorporated in a tablet is released rapidly as the tablet disintegrates because the rate of disintegration affects the dissolution and subsequently the therapeutic efficacy of the medicine. Different formulation factors are known to affect results of disintegration test. The type and amount of excipients used in tablet formulation as well as the manufacturing process are all known to affect both the disintegration and dissolution parameters (Muaz et al., 2009).

\section{Chemical assay}

The results for actual content of different brands of metformin hydrochloride tablets are depicted in Table IV. The USP states that metformin hydrochloride tablets should contain not less than $95.0 \%$ and not more than $105.0 \%$ of the stated amount (USP, 2007). All products of metformin hydrochloride tablets passed as per the USP specification. The highest and lowest drug content was obtained for Metformin Denk (104.85\%) and Brot (97.18), respectively.

Assay for the content of active ingredients is a critical test of quality, as all the physical properties tested are meant to optimize release of the drug from the product. So, no matter how perfect a product may be in terms of physical parameters, failure to meet the standard for content of active ingredients will result in poor quality with adverse consequences (Ogah and Kadejo, 2013).

Pair-wise comparisons of products of metformin hydrochloride tablets were performed by one way analysis of variance (ANOVA) multiple comparisons. Statistical comparison for mean difference of drug content with $95 \%$ confidence interval indicated that there is no significance difference in the drug content of Diabetamin and Bigomet with other products of metformin hydrochloride tablets $(\mathrm{P}>$ 0.05). Similarly, Metformin Denk was not significantly different from Glucomet $(\mathrm{P}<0.05)$. However, Metformin Denk and Glucomet products were significantly different in the drug content from Neomid and Brot $(\mathrm{P}<0.05)$. Such differences in drug content could raise doubts on the general equivalence of the brands.

\section{Dissolution test}

The dissolution profiles of the six brands of metformin hydrochloride tablets are illustrated in Figure 1. According to USP (2007), the amount of metformin hydrochloride released within $30 \mathrm{~min}$ should not be less than $80 \%$ of the stated amount. From the dissolution test results shown in Table V, all the brands of metformin hydrochloride tablets studied released more than $80 \%$ within 30 min except Metformin Denk which has released only $68.39( \pm 0.068)$. Hence, five of the products complied with USP dissolution tolerance limits but Metformin Denk failed to release the stated amount. 
Dissolution of drugs can be influenced by the physicochemical proper ties of the drug substance, the dosage form design, the manufacturing process, and the testing conditions (i.e., apparatus, agitation, medium, etc).
A good in vitro-in vivo correlation can allow the use of in vitro dissolution studies for prediction of product in vivo performance and, therefore, in vitro dissolution profiles can be utilized as a surrogate for in vivo bioequivalence or bioavailability studies.

Table V. Time dependent drug release of products of metformin hydrochloride tablets

\begin{tabular}{lllllll}
\hline Sampling & \multicolumn{7}{c}{ Percent of drug release $(\mathrm{w} / \mathrm{w}) \pm \mathrm{RSD}$} \\
\hline time (min) & Neomid & Bigomet & Met. Denk & Brot & Diabetamin & Glucomet \\
10 & $38.05 \pm 0.02$ & $24.2 \pm 0.037$ & $24.53 \pm 0.05$ & $35.03 \pm 0.02$ & $43.32 \pm 0.09$ & $31.32 \pm 0.08$ \\
20 & $76.49 \pm 0.07$ & $52.97 \pm 0.051$ & $47.20 \pm 0.04$ & $64.47 \pm 0.05$ & $72.43 \pm 0.1$ & $61.97 \pm 0.05$ \\
30 & $88.60 \pm 0.02$ & $81.62 \pm 0.039$ & $68.39 \pm 0.07$ & $85.48 \pm 0.01$ & $81.88 \pm 0.03$ & $80.23 \pm 0.01$ \\
45 & $95 \pm 0.004$ & $89.51 \pm 0.011$ & 79.310 .044 & $96.86 \pm 0.01$ & $90.81 \pm 0.006$ & $95.75 \pm 0.0$ \\
60 & $98.02 \pm 0.005$ & $92.23 \pm 0.01$ & 87.960 .035 & $97.86 \pm 0.01$ & $91.68 \pm 0.009$ & $97.3 \pm 0.01$ \\
\hline
\end{tabular}

It was observed that Brot with the second smaller disintegration time $(6.44 \mathrm{~min})$, showed fast percentage drug release and Metformin Denk with the highest disintegration time (15.69 $\mathrm{min})$, showed low percentage of drug release within 30 min which agrees with the general concept that fast disintegrating tablets release their drugs easily and vice versa. The higher rate of disintegration of tablet dosage forms indicates faster break down of a tablet into smaller particles and thus, enhanced the dissolution of the medicaments into the blood circulation, increasing bioavailability (Chandrasekaran et al., 2011).

Statistical analysis was conducted for the pharamacopoeially specified time, $30 \mathrm{~min}$, using Tukey's one-way ANOVA. The statistical comparison of the release profile of the different products of metformin hydrochloride tablets indicated that at 95\% confidence interval, there is significance difference in the drug release of Metformin Denk with other products of metformin hydrochloride tablets $(\mathrm{P}<0.05)$. In addition, the percent drug releases for Bigomet, Diabetamin and Glucomet at 30 min were significantly different from Neomid $(\mathrm{P}<0.05)$. Similarly, Bigomet was significantly different in the drug release from Glucomet $(\mathrm{P}<0.05)$. However, the percent drug releases for Brot, Bigomet and Glucomet were not significantly different from Diabetamin $(\mathrm{P}>0.05)$.

Statistically, with $95 \%$ confidence interval, some of the products of metformin hydrochloride tablets showed significant difference $(\mathrm{P}<0.05)$, indicating differences in their in vitro drug release that might affect the in vivo bioavailability and the bioequivalence of the products. Thus, the differences in dissolution profiles are likely to reflect potential differences in clinical performance of the products.

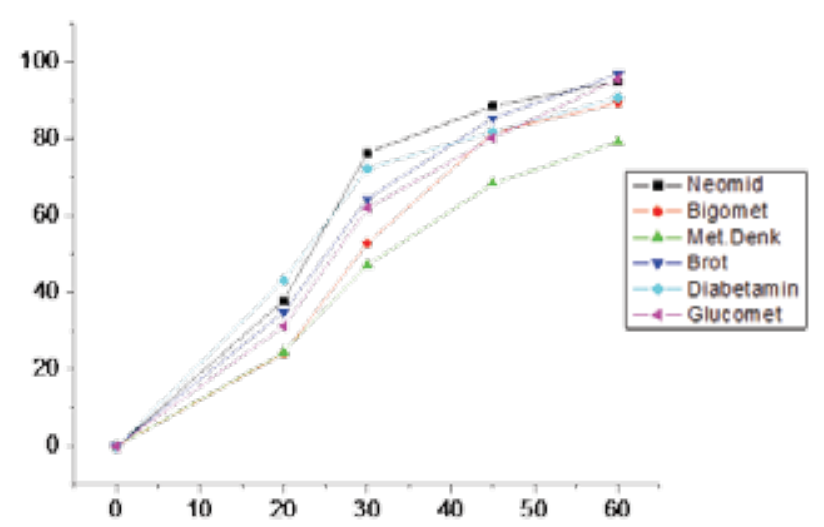

Fig. 1. Dissolution profiles of products of metformin hydrochloride tablets

Comparison of in vitro dissolution profiles of drug products may be accomplished by using a model independent or a model-dependent (curve fitting) approach. In the model-independent approach, the data are described by sample times (e.g.t $\mathrm{t}_{50 \%}, \mathrm{t}_{90 \%}$, mean dissolution time, similarity factor ( $f 2)$, or a dissimilarity factor $(f 1)$.

$t_{50 \%}$ and $t_{90 \%}$ were used as dissolution parameters to compare dissolution profiles of the different brands of metformin hydrochloride tablets. The $\mathrm{t}_{50 \%}$ and $\mathrm{t}_{90 \%}$ are the dissolution parameters that can be utilized to analyze dissolution profile of different pharmaceutical products. The $\mathrm{t}_{50 \%}$ and $\mathrm{t}_{90 \%}$ are the times taken for $50 \%$ and $90 \%$ of the drug to be released respectively. The $t_{50 \%}$ and $t_{90 \%}$ of the different products of metformin hydrochloride tablets analyzed are shown in Table VI. The results showed that, $50 \%$ and $90 \%$ release have been achieved within relatively short period of time for Brot 
Table VI. $t_{50 \%}$ and $t_{90 \%}$ values of products of metformin hydrochloride tablets

\begin{tabular}{lll}
\hline Brand & Dissolution parameters & \\
\hline & $\mathrm{t}_{50 \%}(\mathrm{~min})$ & $\mathrm{t}_{90 \%}(\mathrm{~min})$ \\
\hline Bigomet & 14.623 & 48.577 \\
Diabetamin & 18 & 59.8 \\
Brot & 9.39 & 31.2 \\
Met. Denk & 18.886 & 62.74 \\
Neomid & 10.376 & 34.469 \\
Glucomet & 9.987 & 33.178 \\
\hline
\end{tabular}

$\left(\mathrm{t}_{50 \%}=9.39 \mathrm{~min}, \mathrm{t}_{90 \%}=31.2 \mathrm{~min}\right)$, Glucomet $\left(\mathrm{t}_{50 \%}=9.987 \mathrm{~min}\right.$, $\left.\mathrm{t}_{90 \%}=33.178 \mathrm{~min}\right)$ and Neomid $\left(\mathrm{t}_{50 \%}=10.376 \mathrm{~min}, \mathrm{t}_{90 \%}=34.469\right.$ min) and hence, they are expected to be absorbed and become bio available within a short period of time. Relatively longer $\mathrm{t}_{50 \%}(18.886)$ and $\mathrm{t}_{90 \%}(62.74)$ values have been obtained for Metformin Denk and hence, the product may manifest lower rate and extent of bioavailability in the body.

\section{Conclusions}

This study was aimed to assess quality as well as physicochemical bioequivalence of six brands of metformin hydrochloride tablets marketed in Addis Ababa using in vitro methods. The study confirmed that brands of metformin hydrochloride tablets complied with the official specification for hardness, friability, assay and disintegration. Five brands of metformin hydrochloride complied with the USP dissolution tolerance limits but Metformin Denk failed to release the stated amount.

Statistical comparison for in vitro drug release showed that some of the products of metformin hydrochloride tablets have significant difference $(\mathrm{P}<0.05)$, indicating difference in their in vitro drug release that might affect the in vivo bioavailability and the bioequivalence of the products.

\section{Acknowledgments}

Authors are grateful to the Ethiopian Food, Medicine and Health Care Administration and Control Authority (EFMHACA) for donating metformin standard. Their sincere thanks goes to Addis Ababa University and Wollo University for sponsoring this study.

\section{References}

Bano R, Gauhar S, Naqvi SBS and Mahmood S (2011), Pharmaceutical evaluation of different brands of levofloxacin tablets (250mg) available in local market of Karachi (Pakistan), International Journal of Current Pharmaceutical Research 3: 15-22.

Barbara G, Joseph T, Terry L and Cecily V (2009), Pharmacotherapy Handbook, $7^{\text {th }}$ Ed. Mc Graw Hill, New York, USA, pp 210-2011.

Bastaki S (2005), Diabetes mellitus and its treatment, International Journal of Diabetes and Metabolism 13:111-134.

Bhavanam PR, Surender G, Subhaskar KV and Reddy KV (2010), Comparative in vitro evaluation of commercial metformin hydrochloride tablets, Journal of Innovative Trends in Pharmaceutical Science 1: 152-157.

Chandrasekaran AR, Han CY, Chung ACY, Cheang LW and Ping LS (2011), Post market in vitro equivalency evaluation of paracetamol tablets in Kedah, Malaysia, International Journal of Pharmaceutical Science and Nanotechnology 4: 1403-1407.

Chereson R (1996), Basic pharmacokinetics: bioavailability, bioequivalence and drug selection, available from: http:/www.scribd.com/doc/496701/basic-pharmacoki netics bioavaiabilty y \#scribd [Accessed15/01/2013].

Fahmy S and Gharbieh EA (2014), In vitro dissolution and in vivo bioavailability of six brands of ciprofloxacin tablets administered in rabbits and their pharmacokinetic modeling, BioMed Research International 1:1-8. DOI:org/10.1155/2014/590848

Hailu GS, Gutema GB, Asfaw AA, Hussen DA and Hadera MG (2011), Comparative assessment of the physicochemical and in-vitro bioavailability equivalence of co-trimoxazole tablets marketed in Tigray, Ethiopia, International Journal of Pharmaceutical Sciences and Research 2: 3210-3218.

Katzung BG, Masters SB and Trevor AJ (2012), Basic and clinical pharmacology, $12^{\text {th }}$ Ed., Mc Graw-Hill, USA, pp 737-747.

Khatib O (2006), Guidelines for the prevention, management and care of diabetes mellitus, World Health Organization Regional office for Eastern Mediterranean, EMRO Technical Publications Series 32, Cairo, available from: www.emro.who.int/ dsaf/dsa664.pdf. [Accessed15/04/2013]. 
Kishore KA and Amareshwar P (2012), Quality evaluation and comparative study on tablet formulations of different pharmaceutical companies, Journal of Current Chemical and Pharmaceutical Sciences 2: 24-31.

Muaz J, Gazali K, Sadiq GQ and Tom GM (2009), Comparative in vitro evaluation of the pharmaceutical and chemical equivalence of multi-source generic ciprofloxacin $\mathrm{HCl}$ tablets around Maiduguri metropolitan area, Nigerian Journal of Pharmaceutical Sciences 8: 102-106.

Najib N, Idkaidek N, Beshtawi M, Bader M, Admour I, Alam S, Zaman Q and Dham R (2002), Bioequivalence evaluation of two brands of metformin $500 \mathrm{mg}$ tablets (dialon \& glucophage) in healthy human volunteers, Journal of Biopharmaceutics and Drug Disposition 23: 301-306. DOI:org/ $10.1002 /$ bdd. 326

Odeniyi MA, Adegoke OAA, Adereti RB, Odeku OA and Itiola OA (2003), Comparative analysis of eight brands of sulfadoxine pyrimethamine tablets, Tropical Journal of Pharmaceutical Research 2: 161-167.

Ogah CO and Kadejo FF (2013), Analysis of brands of glibenclamide tablets in Lagos Market, Journal of Innovative Research in Engineering and Sciences 4: 466-471.

Oishi TS, Haque A, Dewan Iand Ashraful I (2011), Comparative in vitro dissolution study of some ciprofloxacin generic tablets under biowaiver conditions by RP-HPLC, International Journal of Pharmaceutical Sciences and Research 2: 3129-3135.

Oishi TS, Nimmi I and Islam SM (2011), Comparative in vitro bioequivalence analysis of some generic tablets of atorvastatin, a BCS class II compound, Bangladesh Pharmaceutical Journal 14: 61-66.
Olusola AM Adekoya AI and Olanrewaju OJ (2012), Comparative evaluation of physicochemical properties of some commercially available brands of metformin hydrochloride tablets in Lagos, Nigeria, Journal of Applied Pharmaceutical Science 2: 41-44.

Poretsky L (2010), Principles of diabetes mellitus, $2^{\text {nd }}$ Ed. Springer Science and Business Media, USA, pp 630-745.

Sahra IB, Marchand-Brustel YL, Tanti JF and Bost F (2010), Metformin in Cancer Therapy: A New Perspective for an old Antidiabetic Drug, Molecular Cancer Therapeutics 9: 1092-1099. DOI: 10.1158/15357163.MCT-09-1186

USP (United States Pharmacopoeia) National Formulary, USP 30/NF 25 (2007), United States Pharmacopoeial Convention Inc., Rockville, Vol. I, MD, USA.

Wild S, Roglic G, Green A and Sicree R (2004), Global prevalence diabetes: Estimates for the year 2000 and projection 2030, Diabetes Care 27: 1047-1053.

Zakeri-Milani P, Nayyeri-Maleki P, Ghanbarzadeh S, Nemati $M$ and Valizadeh $H$ (2012), In vitro bioequivalence study of eight brands of metformin tablets in Iran market, Journal of Applied Pharmaceutical Science 02: 194-197. 